\title{
O uso de RPG como ferramenta no ensino de gêneros textuais
}

na escola

\author{
The use of RPG as a tool in the teaching of textual genders in school \\ Rafael Santos LOPES* \\ Universidade Federal do Pará (UFPA) \\ Secretaria Municipal de Educação do Município de Curralinho
}

\author{
Marcos André CUNHA ** \\ Universidade Federal do Pará (UFPA)
}

\begin{abstract}
RESUMO: Este artigo aborda o tema do uso do RPG como ferramenta no ensino de gêneros textuais na escola. Ressalta-se a produtividade interacionista desse jogo como potencial instrumento que possibilita a produção textual numa diversidade de gêneros, bem como a importância da oralidade, presente no referido jogo, para as práticas de produção escrita, considerando-se as singularidades e posicionamento criativo dos sujeitos alunos. A coleta e análise das informações e teorias obtidas nesse trabalho tiveram como base a bibliografia de profissionais da área da educação que abordaram o RPG em sala de aula.
\end{abstract}

PALAVRAS-CHAVE: gênero textual; RPG na escola; aula de português.

\begin{abstract}
This article addresses the topic of using RPG as a tool in teaching text genres at school. The interactional productivity of this game is emphasized as a potential instrument that allows textual production in a diversity of genres, as well as the importance of orality, present in that game, for the practices of written production, considering the singularities and creative positioning of the subjects students. The collection and analysis of the information and theories obtained in this work were based on the bibliography of professionals in the field of education who addressed RPG in the classroom.
\end{abstract}

KEYWORDS: textual genre; RPG in the classroom; final years of elementary school

\footnotetext{
* Especialista em Metodologia do Ensino de Português e Literatura, professor de português concursado no município de Curralinho no circuito modular das escolas em comunidades ribeirinhas e mestrando no Mestrado Profissional em Letras na Universidade Federal do Pará. E-mail: rafael_2808@ @otmail.com

** Professor Associado vinculado à Universidade Federal do Pará, na Faculdade de Letras do Campus de Castanhal. Colaborador do Programa de Pós-Graduação Interdisciplinar em Linguagens e Saberes da Amazônia. Campus de Bragança/ UFPA. Credenciado no Programa de Pós-Graduação em Rede Nacional (Profletras- Mestrado Profissional). Coordenador do Grupo de Pesquisas das Identidades e Subjetividades da Amazônia Paraense (GEDISPA). Doutor em Análise do Discurso pelo Programa de Pós-Graduação em Língua Portuguesa e Linguística da Faculdade de Ciências e Letras- Universidade Estadual Paulista "Júlio de Mesquita Filho" UNESP-Araraquara. (Linha de Pesquisa Organização e Funcionamento Discursivos e Textuais). E-mail: marcosadcunha@gmail.com.br
} 


\title{
1. A problemática
}

Dentre as três principais concepções de aprendizagem discutidas pela psicologia da educação, destacando-se: a inatista, a behaviorista (ou ambientalista) e a interacionista. Não restam dúvidas de que o interacionismo, surgido a partir de Jean Piaget e Lev Seminovitch, é o mais aceito e reconhecido para o processo de aprendizagem nas escolas, como veremos a seguir.

Para compreendermos o interacionismo sob uma ótica objetiva, podemos utilizar a explicação de Oliveira (2010):

\begin{abstract}
O interacionismo vê o aprendizado como um processo de interação que envolve três fatores fundamentais: o aprendiz, os elementos de sua natureza biológica e o meio ambiente sociocultural em que ele está inserido. $\mathrm{O}$ aluno, sob a perspectiva interacionista, não é mais visto como um ser passivo - ele passa a ser concebido como um sujeito ativo que, para construir seus conhecimentos, se apropria dos elementos fornecidos pelos professores, pelos livros didáticos, pelas atividades realizadas em sala e por seus colegas. (2010, p.28)
\end{abstract}

Concebendo-se o sujeito como um ser ativo se devem buscar novas e inovadoras metodologias, ferramentas e tecnologias de ensino da língua portuguesa, contrapondo-se às práticas do ensino tradicional, na qual o professor fica preso a uma aula expositiva junto ao quadro, esperando que o aluno copie o assunto do dia e resolva questões em seu caderno. Ao contrário, é necessário buscar uma interação real com o sujeito aluno para que ele possa experimentar por meio da prática o conteúdo da aula e sua aplicação no cotidiano e na vida social.

Não é de hoje que há um apelo para a quebra desse tradicionalismo nas aulas de português, que prioriza as aulas baseadas na análise de palavras e frases totalmente fora de contexto, substituindo-as pela utilização de textos. Esses devem ser trabalhados em sua diversidade, vindo, assim, a abordar o maior número possível de gêneros textuais, tendo como matriz dos objetivos do ensino o abandono do estudo descontextualizado da língua. Segundo Antunes (2003), há uma necessidade de mudança de metodologia ainda observável nas aulas de português: 
Um exame mais cuidadoso de como o estudo da língua portuguesa acontece, desde o Ensino Fundamental, revela a persistência de uma prática pedagógica que, em muitos aspectos, ainda mantém a perspectiva reducionista do estudo da palavra e da frase descontextualizadas. (2003, p.19)

E essa contextualização se faz possível com a abordagem de diversos gêneros textuais nas aulas de língua portuguesa, o qual é o foco desse artigo, que visa trazer uma ferramenta pedagógica para viabilizar a contextualização da abordagem de diversos gêneros textuais na sala de aula.

Para uma melhor compreensão do papel do gênero textual nas aulas de português, utilizemos o conceito de Marcuschi (2010):

\footnotetext{
Gênero textual [...] apresenta características sociocomunicativas definidas por conteúdos, propriedades funcionais, estilo e composição característica. [...] os gêneros são inúmeros. Alguns exemplos de gêneros textuais seriam: telefonemas, sermão, carta comercial, carta pessoal, romance, bilhete, reportagem jornalística, aula expositiva, reunião de condomínio, notícia jornalística, horóscopo, receita culinária, bula de remédio, lista de compras, cardápio de restaurante, instruções de uso, outdoor, inquérito policial, resenha, edital de concurso, piada, conversação espontânea, conferência, carta eletrônica, bate-papo por computador, aulas virtuais e assim por diante. (2010, p.23-24)
}

Considerando que Antunes (2003) fala sobre a importância da abordagem de textos e suas respectivas contextualizações nas aulas de português, e que, segundo Marcuschi (2010, p.34), os textos sempre se manifestam num ou noutro gênero textual, esta pesquisa trata da utilidade da abordagem de uma ferramenta pedagógica que pode ser explorada como ponte entre os alunos e os gêneros textuais.

Este artigo é um convite ao professor para sair do quadro e trazer o aluno para um nível de interação cuja experiência tem como objetivo motivar o estudante por meio de atividades lúdicas para que ele tenha contato com o conteúdo programático da disciplina, mais especificamente por intermédio de um jogo, já há muito experimentado em sala de aula, mas cuja origem remonta há algumas décadas desde sua criação: o RPG (Role-Playing Game).

Utilizando o RPG como uma ferramenta pedagógica no ensino e abordagem de gêneros textuais nas aulas de português, o professor tem a oportunidade de contextualizar os textos, simular situações reais e, finalmente, trazer o aluno à participação de forma proativa nas aulas. E mais que isso, incentivar os alunos a 
realizarem pesquisas, produções textuais e praticar sua oralidade em diversas situações que vierem a ser propostas durante o jogo.

A temática do uso do RPG na sala de aula já foi bastante abordada por muitos professores, tanto em artigos científicos, dissertações e teses quanto em eventos e livros. Porém, apesar de uma acalorada discussão a respeito desta ferramenta pedagógica ainda é pouco estudada e debatida no que se refere ao seu uso nas aulas de português, e de sua real possibilidade no uso de ensino de gêneros textuais em sala de aula. Também ainda é pouco refletido a utilização do RPG por professores de diversas disciplinas ( o que não no deteremos nesse artigo).

O RPG como ferramenta pedagógica não é uma temática comumente abordada nas universidades e cursos de formação de professores. Não há uma disciplina voltada para o uso do RPG na sala de aula, e são raros os eventos que associam o RPG à educação. Por conta disso, é natural que muitos professores não tenham a devida intimidade com o RPG para utilizá-lo em suas aulas.

Este artigo é uma pesquisa bibliográfica sobre autores que escreveram a respeito do uso pedagógico do RPG, e sobre obras que tratam do ensino de gêneros textuais nas aulas de português na escola.

Até onde se abre esse leque de possibilidades que o RPG pode fornecer ao professor de português em suas aulas que abordem diversos gêneros textuais? Quais seus efeitos, benefícios e colaboração no processo de ensino-aprendizagem para o aluno na escola? Levantadas estas questões, busquemos um conhecimento mais aprofundado do que é e como funciona o RPG.

\section{Origem do RPG}

O RPG é uma sigla que vem do inglês para Role Playing Game, cuja tradução mais utilizada em português é Jogo de Interpretação de Papéis. Esse jogo surgiu nos Estados Unidos na década de 1970 entre amigos que disputavam um jogo de tabuleiro de guerra. Tal como o clássico War, onde exércitos se confrontam e, após tentar invadir uma fortaleza sem sucesso, um dos jogadores sugeriu que, não um exército, mas um grupo de heróis teria encontrado uma passagem secreta para invadir a fortaleza.

Foi então que os jogadores pararam de controlar exércitos e passaram a controlar um único personagem. E assim nasceu o primeiro RPG: Dungeons \& Dragons, numa 
tradução livre, Masmorras e Dragões, no qual um personagem assume o papel de um herói e, juntamente com seu grupo formado por outros heróis, explora masmorras lutando contra monstros e vilões, encontrando tesouros, ficando mais experiente e forte. Assim, enfrentando até mesmo dragões.

Explorando o conceito e mesmo a compreensão do que é o RPG, podemos, segundo Vieira (2012), conceituá-lo “O RPG é um jogo de contar história e interpretar, um grande faz de conta com regras e leis, no qual cada jogador cria um personagem com características físicas, psicológicas e sociais próprias e passa a interpretá-lo. (2012, p. 14)"

Ao buscarmos o conceito também em Rodrigues (2004) encontramos:

\begin{abstract}
O Roleplaying Game é um jogo de produzir ficção. Uma aventura é proposta por um narrador principal - o mestre - e interpretada por um grupo de jogadores. A ação pode se passar em vários 'mundos': de fantasia medieval, terror ou futurista. Pode também interagir com um universo ficcional preexistente. [...] O jogador assume a identidade de uma personagem e finge sê-la durante o desenrolar da aventura. Esta personagem é construída, elaborada numa ficha, de forma detalhada, trabalhosa, como detalhado e trabalhoso é o caminho da criação. (2004, p.18-19)
\end{abstract}

Ou seja, o personagem que é controlado pelo jogador é construído e configurado numa ficha. Por meio desta ficha, chamada ficha de personagem, são definidas suas capacidades físicas, mentais, sua personalidade, o que sabe fazer e muito mais. Porém, há vários jogos de RPG, e cada um possui um modelo de ficha diferente. Sendo assim, os detalhes de cada personagem ficam a cargo do sistema de RPG que é jogado.

Como foi dito anteriormente, há uma grande diversidade de jogos de RPG, desde o Dungeons \& Dragons, já citado anteriormente, no qual se controlam heróis que podem ser guerreiros, magos, anões dentre outros seres fantasiosos. Também há outros jogos nos quais se pode assumir o papel de heróicos humanos, ou vampiros, lobisomens, fadas, guerreiros jedi. Ainda podemos encontrar uma gama de outras opções que podem ir de um famoso personagem de ficção até mesmo alguém totalmente novo, criado a partir da imaginação do jogador. Cada jogo diferente, dentro do universo dos jogadores de RPG, é chamado de sistema. Cada sistema representa um jogo com seus próprios personagens, regras, fichas, cenários, e o que mais seus livros básicos de regras determinarem para utilizar numa partida ou, como se diz entre os jogadores, numa sessão. 
Para ficar mais claro o desenvolvimento do RPG, este gênero de jogo nasceu a partir do Dungeons \& Dragons, no qual o jogador pode assumir um personagem num cenário de fantasia medieval, um jogo totalmente inspirado no universo criado por $J$. $R$. R. Tolkien, a Terra Média, que deu origem a clássicos da literatura, como a saga $O$ Senhor dos Anéis e $O$ Hobbit, duas produções com sucesso absoluto de bilheterias quando adaptados para o cinema, assim como outros títulos ambientados no mesmo universo. Ou seja, o jogador poderia assumir o papel de um elfo, mago, humano guerreiro ou outro ser presente naquele universo. Após uns anos, as regras do jogo foram revisadas, e isso possibilitou misturar classes de personagens, como ser um elfo mago, ou um anão ladino. E daí surgiu o Advanced Dungeons \& Dragons. Mas os RPGs não pararam por aí, e por isso o Advanced Dungeons \& Dragons se tornou apenas um jogo dentre tantas opções deste gênero.

Outros títulos foram criados e se tornaram tão populares quanto o Advanced Dungeons \& Dragons. A essência do jogo está em assumir o papel de uma personagem, ou seja, se a personagem joga como um mago sábio, normalmente quando se comunica com outro personagem, a personagem fala como se fosse um sábio. A exemplo das brincadeiras de criança, de quando, por exemplo, um menino brinca de polícia e ladrão, e fala como se fosse um policial. Ou quando uma menina brinca de escolinha e assume toda uma postura, imitando a fala de uma professora. Assim ocorre no RPG. E vice versa, por que nâo?

Outro RPG muito popular entre os jovens são os jogos adaptados para $O$ Mundo das Trevas, nos quais há vários jogos ambientados num mesmo universo, ou, como se diz entre os jogadores, num mesmo cenário. Cada jogo apresenta um livro básico, independente. Em um livro, o jogador pode assumir um personagem vampiro; em outro livro pode jogar como mago, também havendo opções para lobisomem, aparições, múmias e changeling (que são as fadas). O jogo das identidades, pode favorecer a construção de pontos de vista por parte dos alunos jogadores.

Muitos RPGs também surgiram a partir de sucessos do cinema, jogos de vídeo games, desenhos animados e quadrinhos. No entanto, dada a repercussão desses jogos, o caminho inverso também foi trilhado, como séries, filmes, desenhos e jogos de vídeo games inspirados em jogos de RPG. O mais emblemático deles é o desenho animado Caverna do Dragão, inspirado em Dungeons \& Dragons. 
Após essa visão panorâmica sobre a origem do RPG e alguns caminhos e ramificações que tomou após sua criação e durante seu desenvolvimento e amadurecimento como gênero de jogo e entretenimento, resultando em seu grande consumo entre os jovens, se estendendo, inclusive, ao público adulto, é necessário compreender a atmosfera em volta do jogo, e como pode ser aproveitado e mesmo potencializado nas salas de aula. Considerando-se também o fato de os RPG(s) abordarem as mais diversas temáticas, que vão desde aventuras de ação até mesmo sessões de jogos predominados pela interpretação, o drama e o suspense.

\section{Jogando RPG}

Após essa introdução inicial sobre a origem do RPG, é importante entender por que este gênero de jogo atrai um público tão diversificado, que vai das crianças, passando pelos adolescentes, chegando até aos adultos. Conforme esclarece Vieira (2012):

\footnotetext{
O jogo envolve o ser humano em qualquer fase de sua vida porque lhe dá a oportunidade de tomar decisões, enfrentar desafios e superá-los. Seja um jogo de bolinha de gude entre meninos, um jogo de "queimada", o escondeesconde, para as crianças; os jogos de carta ou os de mímica para os jovens, ou os jogos de guerra para os adultos, sempre os componentes de atividade e decisão são comuns e atraem. (2012, p.9-10)
}

Assim, podemos deduzir que o jogo se faz presente ao longo de toda a nossa vida. Na infância nós nos divertimos, por exemplo, com brincadeiras menos organizadas, como polícia e ladrão, na qual um menino pode dizer que "matou" o coleguinha, e este, por sua vez, pode negar o fato e afirmar que "disparou" primeiro com sua arma de brinquedo. Já no RPG, a velha brincadeira de faz de conta toma uma postura mais organizada. Há regras para determinar quem atirou primeiro, se o alvo foi atingido, o quanto se feriu e outros fatores que podem ser considerados numa sessão de jogo.

Ricon (2004), ao falar do diferencial que o RPG oferece como jogo para entreter as mais diversas faixas etárias em seu público, assim se manifesta:

No RPG, cada jogador interpreta um dos personagens principais da história. Estamos acostumados com histórias com um único personagem principal, um único herói. No RPG, o raciocínio é outro: trata-se de histórias nas quais um grupo de heróis se reúne com um determinado objetivo - cumprir uma missão, realizar um desejo, executar uma vingança, empreender uma busca 
heroica, enfim, alcançar algum objetivo, explorar um assunto que será demonstrado durante a aventura. (2004, p.16)

Agora vejamos como ocorre e como se monta uma sessão de jogo. Primeiramente, há uma divisão elementar entre os participantes do jogo. Há jogadores que assumem os personagens, e estes irão controlar uma pessoa ou criatura. Um jogador irá "incorporar" uma personagem e assumir suas ações, decisões e discursos. Ou seja, estamos falando dos heróis e heroínas da aventura. E há um único jogador que assumirá um posto conhecido como Mestre, Narrador ou Mediador.

Este jogador diferenciado, mais conhecido como Narrador, tem um papel que foge da proposta dos jogadores-personagens. Assim como no clássico jogo Banco Imobiliário, a exemplo de muitos outros jogos de tabuleiro, onde se tem o banqueiro, que é responsável pelas transações financeiras, o Narrador também não "se mistura" com os demais jogadores. Seu papel será o de narrar a aventura, em outras palavras, o de inserir os jogadores no universo onde viverão os desafios com seus personagens.

Ricon (2004) explica de forma muito precisa o papel do Mestre no jogo de RPG:

O RPG é jogado em grupo. Um dos jogadores assume um papel especial, tornando-se o Mestre do jogo. [...] Ele é chamado Mestre por ser um Mestre de Cerimônias, aquele que faz o show acontecer. Ele é como o homem no centro do picadeiro que diz: "Respeitável público!". Ele vai guiar os jogadores ao longo da aventura. Como ele faz isso? Numa história comum, ele seria o narrador. [...] O Mestre descreve o cenário e os personagens secundários - os extras, os coadjuvantes etc. - que vocês vão encontrar durante a aventura. Ele vai descrever brevemente o ambiente no qual vocês estão, e cada jogador vai interagir com aquele ambiente. (2004, p.16)

Apresentado o papel do Mestre no RPG, vamos aos passos a serem seguidos para uma primeira sessão. Antes de a aventura iniciar, há um momento que pode ser vivido pelos jogadores, ou o próprio narrador pode antecipar-se e apenas distribuir a criação de personagens os quais irão participar da sessão. Vieira (2012, p.25) defende esta etapa como importante momento para quem pretende viver uma das aventuras: "Sempre considerei a elaboração do personagem um momento crucial, até porque, como psicólogo, acredito que os personagens são de alguma forma projeções do próprio jogador”. Além dos jogadores terem um primeiro contato com as regras do jogo, eles também terão contato com as fichas dos personagens, um dos primeiros gêneros textuais, entre alguns, a serem utilizados quando se decide utilizar o RPG no ensino de Português. 
Após a fase de criação de personagens, o narrador precisa ter uma aventura pronta. Pode ter a aventura em mente, ou ter anotações de um roteiro, mas é preciso estar ciente de que nem sempre o roteiro é seguido como planejado, já que uma das principais características do jogo é o improviso e a aleatoriedade, pois os jogadores, assim como os personagens, têm o direito ao livre arbítrio de suas ações, e estas, por sua vez, nem sempre são bem sucedidas.

Tenhamos em mente que jogar RPG nos remete a uma tradição tão antiga quanto à comunicação oral humana, que diz respeito às narrativas dos contadores de história. Este é o pilar que rege os jogos de RPG. Podemos, sem esforço, imaginar uma partida de RPG com uma pessoa contando uma história a várias pessoas em volta de uma fogueira. Porém, com algumas diferenças sutis, pois os espectadores também interagem com a história que está sendo contada, uma vez que eles fazem parte dela.

Tendo os jogadores criado um personagem o qual irão interpretar. E, tendo o Narrador criado uma aventura para ser vivida por esses personagens, já podemos iniciar a aventura. $\mathrm{O}$ Mestre irá descrever a situação em que os jogadores se encontram: o local, o horário, quem está em sua volta, se eles estão na companhia de outros jogadores, quais deles ou de todos etc. A aventura é narrada e o Mestre pode pedir que o jogador interaja com alguém ou decida tomar alguma atitude. E então, será que o personagem terá sucesso em alguma ação? Como é decidido, por exemplo, se um cavaleiro consegue saltar com seu cavalo por cima de um tronco e cortar o caminho para alcançar uma carruagem?

Então, no RPG há a imprevisibilidade, tanto para os jogadores-personagens quanto para o Mestre. Ou seja, verifica-se a aleatoriedade das resoluções. Normalmente os jogos de RPG decidem se um personagem teve sucesso através de um lance de dados, porém, não há apenas os tradicionais dados de seis faces. Nos jogos de RPG, podem ser encontrados dados também de 4 lados, 10, 20 e até 100 lados. Mas não apenas eles são usados como métodos de decisão de aleatoriedade. Há opções decididas por um lance de moeda, por cartas, ou até mesmo por decisão do narrador a partir do que sua ficha determina que ele pode, ou não, fazer. 


\section{Aplicando numa sala de aula}

Agora que já foi apresentada uma visão panorâmica sobre o RPG e seus funcionamentos, é hora de trazermos para um contexto em que ele é aplicado em sala de aula.

Um professor precisa apresentar a proposta para os alunos, explicar a todos sua ideia e seus objetivos com esta ferramenta de aprendizado lúdico. Há a possibilidade de que os alunos não conheçam o gênero. Tanto quanto a possibilidade de haver jogadores entre os estudantes. Estes podem se mostrar aliados importantes para elucidar dúvidas a respeito do jogo entre os demais alunos.

O professor também precisa ter em mente o sistema que irá adotar para aplicar o RPG em sala de aula. Há sistemas de RPGs pedagógicos já criados por educadores e que são completamente voltados para usar em sala de aula. Também há sistemas voltados para o lazer, mas que podem ser usados na escola com pouca ou nenhuma adaptação para o contexto educacional.

Um dos primeiros passos a serem seguidos para se iniciar uma sessão de jogo é a criação dos personagens dos jogadores. Estes precisam preencher a ficha de personagem, Dessa forma, tem-se contato com o primeiro gênero textual quando se joga RPG. A ficha contém informações do personagem. Nesse caso, pode-se falar em idade, nome, posição na sociedade, atributos e habilidades. Tudo sendo preenchido sob as regras do jogo.

Juntamente com a ficha, também há a necessidade de se criar um histórico sobre o personagem em jogo. Aí há a criação de uma biografia e a descrição do herói ou heroína. Note-se que antes mesmo de se iniciar o jogo, os jogadores já têm contato com gêneros textuais que trabalham sua produção textual, criatividade e regras.

Caso o professor considere que os alunos estejam bem engajados, eles poderiam até mesmo desenhar seus personagens. Uma vez que o desenho é uma forma de linguagem não verbal. Daí pode expressar, além da tradução da visão de mundo do aluno jogador em torno da temática escolhida. Nesse caso, a imagem desenhada pode indicar um personagem que possui uma posição na sociedade em que foi criado, como uma profissão, função ou costume. Em prosseguimento à criação dos personagens e todos estando prontos para iniciar a primeira sessão de RPG, eis que se inicia o jogo propriamente dito. 
O RPG é um gênero de jogo cuja essência é a imaginação e a contação de histórias. Fica a cargo do mestre a criação de uma aventura para ser vivida pelos jogadores. Cabe ao professor decidir se há estudantes que poderiam assumir o papel de mestre ou, ele mesmo, assume a função de mestre, o que é mais recomendável se os alunos e alunas forem iniciantes neste gênero de jogo. Eis que, para o mestre saber como dividir uma aventura de forma organizada, Campbell (1949), em sua obra que inspirou até mesmo a saga de sucesso mundial Star Wars (Guerra nas Estrelas), criada por George Lucas, traça a jornada que os heróis normalmente percorrem:

\footnotetext{
Um herói vindo do mundo cotidiano se aventura numa região de prodígios sobrenaturais; ali encontra fabulosas forças e obtém uma vitória decisiva; o herói retorna de sua misteriosa aventura com o poder de trazer benefícios aos seus semelhantes. (1949, p. 36)
}

Campbell (1949) encontra elementos em comum a todos os heróis, e, assim, criou o conceito do monomito, que é uma jornada cíclica presente nos mitos, e frequentemente aplicada nas aventuras contadas nos livros de literatura, nos filmes, séries e, porque não, nas aventuras de RPG. Nesse caso, o grupo de heróis irá justamente ser arrastado para uma aventura épica cheia de desafios, perigos, e uma série de fatores que enriquecerão a narrativa. Campbell (1949) ainda diz:

Nas vigorosas narrativas dos gregos ou nas lendas majestosas da Bíblia, a aventura do herói costuma seguir o padrão da unidade nuclear acima descrita: um afastamento do mundo, uma penetração em alguma fonte de poder e um retorno que enriquece a vida. (1949, p. 40)

Tendo em mente a aventura que será vivida pelo grupo de heróis, o professor tem a liberdade/possibilidade de inserir os gêneros textuais que desejar utilizar na atividade em sala de aula. Isto queremos então destacar. Eis algumas sugestões:

CARTA: algum personagem pode receber uma carta que sirva de gancho para iniciar a aventura. Assim como pode precisar escrever uma carta durante uma viagem com uma mensagem para sua família, amigos ou para um líder. A carta deve ser lida na sessão de jogo para que esteja bem inserida no enredo da jornada.

DIÁRIO: este gênero pode estar presente ao longo da aventura, a exemplo de um trecho encontrado sobre a mesa de uma cabana, navio, laboratório ou onde convier. É interessante que os jogadores também mantenham diários dos seus personagens. 
POESIA: a poesia pode aparecer entre personagens cantores, bardos ou artistas que acompanhem a trupe de aventureiros. Podem-se utilizar poesias de alguma geração romântica, cantigas de amigo ou de amor, ou algum momento da história da literatura que se queira abordar na aventura. Também há a possibilidade de os aventureiros ajudarem a compor ou completar uma poesia.

TEXTOS JORNALÍSTICOS: estes textos podem ser inseridos na aventura, inclusive para mostrar que as ações dos personagens estão influenciando a mídia e a imprensa, além de se tornarem notícia local.

RELATÓRIOS: este texto pode ser inserido na aventura para dar pistas para os aventureiros, além de existir a possibilidade de os heróis escreverem relatórios para um líder como um monarca, um oficial ou alguém que esteja liderando a aventura. Convém lembrar também que o relatório pode ser usado também em sua forma oral.

FÓRMULAS E RECEITAS: talvez em algum momento da aventura os heróis precisem produzir um antídoto ou criar um veneno ou elemento químico para atingir um objetivo. Neste momento, eles poderão entrar em contato com receitas para saber que ingredientes precisam ter em mãos, e como irão utilizá-los para produzir o que desejam.

Enfim, há uma grande variedade de gêneros textuais que podem ser explorados em uma sessão de RPG. Tais como e-mails, listas, bulas de remédio, manuais de instrução, mapas, quadros, gráficos, outdoors, redes sociais e quaisquer outros que o professor deseje inserir e trabalhar com sua turma. O limite é apenas a imaginação e a criatividade. E mais, todos os gêneros aparecem como necessários para efetivação do jogo e de uma interatividade social, demandas culturais e mesmo psicológicas em que se pode inserir os alunos/alunas jogadores.

\section{Dificuldades e problemas a superar}

O RPG em uma situação normal de jogo raramente ultrapassa os sete jogadores. Porém, numa sala de aula, podemos encontrar uma quantidade significativamente maior de alunos. Nesse caso, o professor precisa seguir um objetivo: o de simplificar o jogo. Daí, deve evitar sistemas complexos e sobrecarregado de regras para cada tipo de situação que se possa apresentar. Desse modo, evita-se o risco de o professor pausar a sessão para fazer uma prolongada e demorada consulta ao livro de regras e, se isso acontecer sucessivamente, acaba travando a experiência pedagógica em sala de aula. 
Caso o professor opte por um sistema detalhista, precisará aplicar o que os jogos de RPG costumam chamar de Regra de Ouro. Ou seja, o mestre, narrador ou mediador tem o poder de excluir quaisquer regras que achar conveniente para que a sessão possa fluir de maneira harmônica, assim como criar regras para que o jogo possa atender as necessidades dos jogadores. Essa flexibilidade do jogo mostra-se oportuna para a diversidade de níveis e situações de ensino.

Ainda sobre a importância da simplificação das regras do sistema adotado, podemos citar os esclarecimentos de Marcatto (2004):

\begin{abstract}
O RPG é jogado em grupos pequenos de seis a oito pessoas, e numa classe temos 30 ou 40 alunos. A primeira regra é a simplificação. Devemos optar sempre pela simplicidade, e não pela complexidade. Não é a complexidade, não é a criação de um monte de regras e de características de personagem que vai tornar a aventura mais interessante. Isso não é necessário. Podemos ter uma aventura muito interessante sem o uso de dados, características de personagem e aquelas coisas que dificultam o trabalho do professor com grupos grandes. É possível. (2004, p.163)
\end{abstract}

Há algumas opções que podem possibilitar a jogabilidade com um grande número de jogadores. Uma delas seria dividir a turma em vários grupos e daí trabalhar separadamente cada grupo. Caso alguns alunos conheçam o sistema ou se estiverem capacitados para "mestrar" uma mesa de RPG, é possível ter várias sessões acontecendo simultaneamente na sala de aula.

Outra possibilidade seria dividir personagens entre os grupos, havendo em cada grupo um único personagem a ser controlado. Esta divisão poderia ser feita também com fileiras inteiras de alunos. Ou, determinar que todos estejam juntos num único local, e suas ações sejam conjuntas como uma grande massa agindo de forma unida, como se integrassem a tripulação de uma nave espacial ou uma caravela. Marcatto (1996) também trata de sugerir uma solução para esta questão:

\footnotetext{
Uma boa solução é trabalhar com subgrupos. Uma classe de 30 alunos pode ser dividida em seis grupos de cinco alunos. Cada grupo irá representar um personagem. O professor deverá coordenar a atuação de seis personagens e não de 30. A decisão sobre o que o personagem vai fazer é problema de cada grupo. Para evitar conflitos de opiniões sobre a ação do personagem, algum método de decisão deverá ser considerado. A votação pode ser a forma mais indicada quando não houver consenso. (1996, p.78-79)
} 
Vieira (2012) faz uma nova sugestão. A autora também ressalta que o RPG é jogado, tradicionalmente, entre 4 a 6 jogadores. Porém, numa sala de aula podemos encontrar uma média de 40 alunos. Então, faz a seguinte sugestão:

\begin{abstract}
Sobre os alunos, percebi que a prática que mais funciona é agrupá-los em equipes. Tomemos como exemplo uma sala de 40 alunos. O professor os deixa se organizarem em 8 equipes de 5. É importante que cada aluno tenha seu personagem a ser interpretado. É muito curioso e interessante notar a relação de afeto que eles desenvolvem com esse personagem com o passar do tempo. Uma vez as equipes montadas e os personagens criados, a dinâmica do jogo pode ser iniciada. A questão que facilita a vida do professor é que ele acompanhará as equipes durante a aventura do jogo, e não os jogadores isoladamente. Ou seja, ao decidirem ir a algum lugar do mapa da aventura, por exemplo, cada equipe deverá se mover conjuntamente. Chegando nesse lugar do mapa é que cada um poderá fazer a ação que julgar necessária para seu personagem. (2012, p.100-101)
\end{abstract}

Podemos notar que há uma gama de opções oferecidas por educadores que pesquisaram o RPG como ferramenta pedagógica. Sendo assim, é importante que o professor opte por uma alternativa que seja mais adequada para a sua turma. Não apenas sobre as opções já sugeridas, mas que adote a Regra de Ouro: faça as alterações que julgar necessárias para favorecer a jogabilidade e fruição da sessão de jogo em sala de aula.

Outra situação que pode dificultar a aplicação do RPG em sala de aula é a falta de interesse de alguns alunos com a metodologia. Alguns estudantes podem ser tímidos a ponto de não desejarem interagir verbalmente com outros jogadores. Também há a pura e simples falta de desejo de participar, isto devido não haver certa identificação com o jogo. A postura flexível e motivadora junto aos interesses do grupo sempre deve ser buscada pelo professor/mediador.

A participação precisa ser de livre e espontânea vontade por parte dos alunos. Caso contrário, a experiência pode fracassar com a falta de atenção, conversas paralelas e interrupções com temáticas que fujam do foco do jogo. Diante desta situação, Marcatto (1996) recomenda:

\footnotetext{
A participação deve ser livre. Não se pode forçar ninguém a divertir-se. Os alunos forçados a participar irão atrapalhar o andamento da aventura e, provavelmente, prejudicarão todo o grupo.

Mesmo quando o aluno aceite fazer parte do grupo jogador, mas não participe ativamente, não se deve exigir que o faça. Pode-se estimulá-lo, mas com cuidado.
} 
O RPG valoriza a iniciativa e decisão do jogador. Portanto, sua filosofia básica é a de que cada personagem tenha uma contribuição a dar. Se o aluno não deseja "dar", isso deve ser respeitado. O respeito é uma regra fundamental e obrigatória. (1996, p.49)

Porém, os alunos que não desejam participar de forma ativa do jogo, podem ainda assumir um papel periférico na aventura, com título de personagens-observadores, neste caso, podem sugerir consequências de algumas ações, ou simplesmente assumir o papel de coadjuvantes ou meros figurantes na aventura.

\title{
6. Conclusão
}

Conforme pudemos perceber até aqui, o RPG é um gênero de jogo predominantemente oral. A contação de história é o pilar que sustenta esta prática. Assim sendo, a oralidade precisa e deve ser explorada para as implicações pedagógicas que possam ser alcançadas com a prática. Desse modo, Antunes (2003) sugere que:

\begin{abstract}
Aceitar o caráter interacional da oralidade e sua realização em diferentes gêneros e registros textuais leva o professor de português a intervir para que o trabalho com a oralidade tenha as características que passamos a enumerar: uma oralidade orientada para a coerência global [...] uma oralidade orientada para a articulação entre os diversos tópicos ou subtópicos da interação [...] uma oralidade orientada para as suas especificidades [...] uma oralidade orientada para a variedade de tipos e de gêneros de discursos orais [...] uma oralidade orientada para facilitar o convívio social [...] Uma oralidade orientada para se reconhecer o papel da entonação, das pausas e de outros recursos suprassegmentais na construção do sentido do texto [...] uma oralidade que inclua momentos de apreciação das realizações estéticas próprias da literatura improvisada, dos contadores e repentistas [...] uma oralidade orientada para desenvolver a habilidade de escutar com atenção e respeito os mais diferentes tipos de interlocutores. (2003, p.100-105)
\end{abstract}

Notemos que há uma riqueza de opções para se explorar a oralidade oferecida pelo RPG como ferramenta pedagógica. Também destaquemos a compreensão de que a escrita propositiva, assim possível de proporcionar o posicionamento e a criatividade dos sujeitos alunos, encontra-se de modo efetivo na relação com a oralidade e sua bastante e diversa singularidade identitária.

Já com relação aos textos escritos, o RPG abre um leque muito grande para o uso de gêneros textuais no jogo. Hoje há um apelo muito maior para o uso do texto, inclusive como materialidade formal para o posicionamento discursivo nas aulas de português. Essa prática se sobressaindo ao uso de estudos de frases descontextualizadas, 
mesmo nas aulas de gramática normativa. Com relação à importância da utilização dos gêneros textuais nas aulas de português, Oliveira (2010) aborda o gênero textual como:

\begin{abstract}
São textos empíricos, ou seja, textos concretos, que circulam socialmente. Os textos que circulam realizam funções comunicativas diversas: convidar, persuadir, dissuadir, ameaçar, informar, solicitar, autorizar, convocar, descrever, instruir, ordenar, entreter, ofender, desculpar-se, agradecer, protestar etc. Por essa razão, apresentar gêneros textuais diversos aos estudantes é essencial para o desenvolvimento de sua competência comunicativa e de suas habilidades de ler e produzir textos. $(2010, \mathrm{p} .84)$
\end{abstract}

Sendo assim, destacamos a importância da abordagem dos gêneros textuais nas aulas de língua portuguesa. Marcuschi (2010) também corrobora declarações de Olivera (2010) ao deixar claro que:

Tendo em vista que todos os textos se manifestam sempre num ou noutro gênero textual, um maior conhecimento do funcionamento dos gêneros textuais é importante tanto para a produção como para a compreensão. Em certo sentido, é esta ideia básica que se acha no centro dos PCNs (Parâmetros Curriculares Nacionais), quando sugerem que o trabalho com o texto deve ser feito na base dos gêneros, sejam eles orais ou escritos. (2010, p. 34-35)

O RPG, apesar de sua origem e objetivo ser voltado para o lazer, o entretenimento, revela-se uma potente ferramenta para ser utilizada como um instrumento de uso pedagógico. Tendo em vista a importância que o uso dos gêneros textuais nas aulas de português assumiu a partir da criação dos Parâmetros Curriculares Nacionais, o professor pode explorar esta tecnologia educacional em suas aulas, em especial, percebendo que sua aplicação dispensa o uso e a necessidade de vastos recursos financeiros ou de alta tecnologia.

Embora, o RPG seja uma ferramenta ainda pouco pesquisada, estudada e aplicada em sala de aula, reafirmamos, como já foi dito no início desse artigo, que não é uma novidade tão recente, assim como não é um experimento inédito nas aulas de Português. Nesse sentido, Pavão (2000, p.18) fala do RPG: “O que é exatamente, RPG? Professores de áreas diversas apropriam-se dele como instrumento didático. Profissionais da área de Letras tomam-no como objeto de pesquisa". Talvez, fique o destaque desse jogo para os estudos da linguagem.

Este trabalho de pesquisa bibliográfica teve, portanto, como objetivo principal apresentar o RPG como instrumento pedagógico no uso do ensino de gêneros textuais 
em turmas de sexto ao nono anos. Alguns gêneros foram exemplificados para proporcionar uma visão panorâmica de como esta ferramenta educacional pode ser abordada nas aulas de português. Para isto, algumas das principais obras publicadas que associam o RPG com a educação foram analisadas para contribuir com o uso deste instrumento lúdico nas aulas de português.

Enfim, o RPG na sala de aula é um tema rico que precisa ser mais explorado e debatido, especialmente nas salas de aula dos cursos de formação de professor, em que a metodologia voltada para o uso de jogos no ensino da linguagem ainda se faça tão negligenciada.

Conforme foi demonstrado em nossa pesquisa, o RPG é uma importante ferramenta pedagógica que pode ser utilizada com os estudantes do ensino básico (fundamental e médio). Sendo assim, é relevante capacitar os profissionais da educação, incluindo os professores de língua portuguesa ainda em seu período de formação acerca do uso dessa importante ferramenta pedagógica. 


\section{REFERÊNCIAS}

ANTUNES, Irandé. Aula de Português: encontro \& interação / Irandé Antunes, - São Paulo: Parábola Editorial, 2003 - (Série Aula;1)

CAMPBELL, Joseph, 1904-1987. O herói de mil faces / Joseph Campbell; tradução Adail Ubirajara Sobra. - São Paulo: Pensamento, 2007.

MARCATTO, Alfeu. Saindo do Quadro / Alfeu Marcatto. - São Paulo: A. Marcatto, 1996.

MARCUSCHI, Luiz Antônio. Gêneros Textuais: definições e funcionalidade. In: DIONÍSIO, Angela Paiva; MACHADO, Anna Rachel; BEZERRA, Maria Auxiliadora (Org.). Gêneros Textuais e Ensino. São Paulo: Parábola Editorial, 2010.

OLIVEIRA, Luciano Amaral. Coisas que todo professor de português precisa saber: a teoria na prática / Luciano Amaral Oliveira. - São Paulo: Parábola Editorial, 2010.

PAVÃO, Andréa. Aventura da leitura e da escrita entre mestres de Roleplaying Games (RPG) / Andréa Pavão - São Paulo : Devir, 2000

RODRIGUES, Sonia, 1955- Roleplaying game e a pedagogia da imaginação no Brasil: primeira tese de doutorado no Brasil sobre o roleplaying game/Sonia Rodrigues. - Rio de Janeiro; Bertrand Brasil, 2004 210p.

Simpósio RPG \& Educação (1. : 2002: São Paulo) Anais do I Simpósio RPG \& Educação / Organização: Maria do Carmo Zanini; São Paulo : Devir, 2004.

VIEIRA, Matheus. RPG \& Educação: pensamentos soltos / Matheus Vieira, ilustrações de Fernando Alves - Curitiba: Íthala, 2012. 